\title{
Employing the Church as a Marketer of Cancer Prevention:
}

\author{
A Look at a Health Promotion Project Aimed to Reduce Colorectal Cancer Among African \\ Americans in the Midwest
}

Crystal Y. Lumpkins, PhD, Candice R. Coffey, MD, Christine M. Daley, PhD, MA, SM, and K. Allen Greiner, MD, MPH

Department of Family Medicine, University of Kansas Medical Center, Kansas City, Kansas (Drs Lumpkins, Coffey, Daley, and Greiner); and the William Allen White School of Journalism and Mass Communications, Lawrence, Kansas (Dr Lumpkins).

\begin{abstract}
Health promotion programs designed to address colorectal cancer disparities among African Americans are increasing. Unfortunately, this group still shoulders a disproportionate mortality burden in the United States; these numbers are also reflective of colorectal cancer (CRC) disparities in the Midwest. The purpose of this study was to extrapolate results from in-depth interviews and brief surveys on the effectiveness of the church as a social marketer of CRCprevention messages. Results show that pastors believe the congregation has limited knowledge about CRC risk and prevention; they also believe the church can improve cancer-prevention communication among members and those affiliated with the church.
\end{abstract}

\section{Keywords}

African Americans; church based; faith based; health promotion; social marketing

Colorectal Cancer (CRC) is the third most commonly diagnosed cancer and third leading cause of cancer death among men and women in the United States. The American Cancer Society estimated that 141210 new diagnoses and 49380 deaths would result from CRC in 2011. ${ }^{1}$ African Americans suffer higher incidence and mortality from CRC than any other racial/ethnic group. ${ }^{2-4}$ The incidence of CRC and mortality rates in African Americans are $20 \%$ and $45 \%$ higher, respectively, than those in whites. ${ }^{1} \mathrm{~A}$ look at 2 states in the Midwest shows incidence and mortality rate disparities as well. Among African Americans, the screening prevalence was $58.3 \%$ in the state of Kansas and 57.4\% in the state of Missouri between 2006 and 2008. ${ }^{1}$ These rates fall below the national screening prevalence average and put African Americans at greater risk of mortality from CRC.

Colorectal cancer is preventable and treatable if detected early; nearly $90 \%$ of individuals 50 years and older who are diagnosed with early stages of CRC survive. ${ }^{1}$ Although early detection through screening is vital to finding and treating colorectal cancer, many African Americans do not screen because of various barriers. This group is more likely to be diagnosed with CRC in advanced stages and they often hold negative perceptions toward

Copyright @ 2013 Lippincott Williams \& Wilkins.

Correspondence: Crystal Y. Lumpkins, PhD, University of Kansas Medical Center, School of Medicine, Family Medicine Research Division, Kansas City, KS 66160 (clumpkins@kumc.edu).

Supplemental digital content is available for this article. Direct URL citation appears in the printed text and is provided in the HTML and PDF versions of this article on the journal's Web site (journals.lww.com/familyandcommunityhealth/).

The authors declare no conflict of interest. 
screening ${ }^{4,5}$ and fatalistic views about cancer. ${ }^{6}$ In other instances, socioeconomic barriers, limited access to medical treatment, limited knowledge of cancer risks, fear and mistrust among medical personnel, and lack of patient provider communication ${ }^{7}$ may delay or completely immobilize African Americans seeking screening. ${ }^{4,8}$ These barriers may prevent this population from recognizing or acting on symptoms and bowel problems that might ultimately lead to opportunities for diagnosis. Overcoming such barriers may lead these individuals to seek screening and diagnostic tests and increase chances for survival.

Research indicates African Americans view religion and spirituality as important factors in life; particularly when making decisions about healthy living and prevention of lifethreatening disease and cancers. ${ }^{9}$ Because of the church's central role in African Americans' lives and religious practices in African American culture, it is plausible that church-based health promotion programs (CBHPPs) are effective in addressing health disparities among African Americans. The purpose of this article was to analyze results from a communitybased participatory research project that investigates the church's role as a social marketer and health promoter of colorectal cancer risk and prevention messages among African Americans.

\section{Religion and health among African Americans}

Religion has traditionally and historically been a factor interwoven in African American culture. ${ }^{10,11}$ A 2007 Pew Report states that African Americans think of themselves as a religious people and believe it is an extremely important facet in their lives. ${ }^{12}$ The church's prominent and influential role in the community has also positioned it as a natural partner to engage in social and civic activities. In a national survey of more than 2000 Black churches ( 935 churches), almost half (43.5\%) participated in civil rights organizations such as the National Association for the Advancement of Colored People and 177 of those churches $(8.2 \%)$ were involved in addressing health-related agencies and health problems. ${ }^{10}$

Public health scholar Jeffrey Levin pointed out the importance and influence of the pastor in the African American church and how that position can be used to strategically promote health among congregants. ${ }^{13} \mathrm{He}$ conceptualizes the role of the Black pastor in preventive health and how these spiritual leaders could be integral to health behavior change. This involvement places the pastor in an active role in preventive medicine on multiple levels including the tertiary, secondary, and primary levels of prevention. ${ }^{13}$ These health-related roles have made pastors "ideal people to take part in planning, promoting, and delivering preventive health care in the Black community."13

The reach of the African American church and pastor collectively has the potential to galvanize African Americans to positive health behavior change. Watson and colleagues ${ }^{14}$ argue the church and faith communities are largely untapped resources for promoting healthy lifestyles among African Americans. This type of influence, faith-based and community-focused, signifies the value, trust, and credibility of the African American church and why it is often viewed as a change agent in the African American community. Through strategically developed health promotion programs with the church and by the church, targeting African Americans concerning CRC screening can be successful.

\section{The strength of church-based health promotions programs and social marketing}

In 2002, Peterson and colleagues ${ }^{15}$ identified 7 key elements in the literature that summarize the strength and success of CBHPPs to reach vulnerable populations. Those included partnerships, positive health values, availability of services, access to church facilities, 
community-focused interventions, health behavior change, and supportive social relationships. Several CBHPPs have shown to be successful among African Americans. The WATCH or Wellness for African Americans Through Churches, a church-based health promotion research study, involved members and pastors with improving nutrition, physical activity, and CRC screening among rural African Americans. ${ }^{16}$ These efforts were accomplished via printed newsletters, videos, and the creation of social support networks. Videos and lay health advisors both showed to have an impact on church members and thus on CRC screening behavior. Other CBHPPs such as Black Churches United for Better Health; Eat for Life; Healthy Body, Healthy Spirit; and Body and Soul also involved health promotion strategies to impact behavior among African Americans in the church setting. ${ }^{17}$ These strategies were largely successful in that the promotion was incorporated at multiple levels (eg, intrapersonal, social network, organizational and environment) and followed a socioecological perspective. Given the church's role as a strong and enduring organization in the African American community and its impact on several aspects of African American culture and way of life, the value of a multiple leveled approach is ideal. Under a social marketing framework, promotion would occur not only internally (inside the church) but also externally with the goal of reaching a segment of the population or community with the intent of marketing prosocial ideas. ${ }^{18}$ In addition, the goal is not only to educate and inform but also to change behavior. ${ }^{19}$

By definition, social marketing is "the application of proven concepts and techniques drawn from the commercial sector to promote changes in diverse socially important behaviors such as drug use, smoking, sexual behavior ...." 18 The concept of social marketing is based on the idea of how messages are distributed to a specific group of individuals or a target audience by way of the marketing mix (4Ps) that include place, price, product, and promotion. The techniques/methods of social marketing are largely derived from behavioral theory, persuasion psychology, and marketing science ${ }^{20}$ Social marketing methods, applied on a population level, can be beneficial in promoting public health because of the emphasis on human behavior and how a specific group of individuals will most likely accept or reject marketed messages. Social marketing methods used to disseminate these messages range from strategies using the mass media to message placement of promotional materials in health clinics and doctor's offices. Social marketing then occurs in a step-by-step process allowing for a well-thought out plan to impact a specific audience about a specific health problem.

The church and pastor via CBHPPs essentially become part of an effort to market and "sell" the idea of screening to the mass faith audience while marketing to individual churches simultaneously. The church in this case is not only the marketer of socially marketed goods and services but also the recipient and buyer as well.

Social marketing, a multi-leveled approach to impact health behavior, may prove beneficial as a key health promotion strategy to impact CRC screening among African American faith populations.

\section{AIM}

The primary aim of the study was to elicit information on the social marketing concept and feasibility of a culturally and religiously targeted CRC intervention on CRC screening promotion with pastors. The following research questions (RQs) were posed:

RQ (1): How do African American pastors view the church as a social marketer of colorectal cancer screening promotion materials? 
RQ (2): How do African American pastors view church-sponsored colorectal cancer screening promotion materials compared with scientifically sponsored materials?

\section{METHODS}

\section{Setting}

The study was conducted at 7 churches throughout urban and suburban areas of major metropolitan cities in Kansas and Missouri. Although data collection took place at different areas (eg, fellowship hall, Sunday School classroom) within each church, those areas were generally areas that the church membership held large fellowship activities. Human subjects approval was also obtained from the primary author's health science center internal review board prior to data collection.

\section{Sample inclusion and exclusion selection}

A total of 17 clergy from the Kansas City, Missouri, and Kansas City, Kansas urban core and suburban area participated in this formative study. Eleven clergy completed a community assessment survey immediately following an informal ongoing series of pastor lunch health discussion sessions sponsored by the primary author's medical institution. An additional 6 clergy participated in semistructured interviews; only 1 pastor completed both the community assessment survey and in-depth interview.

Participants were recruited on the basis of the following criteria: (a) African American and (b) pastor of a predominately African American church in the Kansas City, Missouri, or Kansas City, Kansas areas. The inclusion criteria for the pastor participants also included holding the senior pastor position for a minimum of 5 years where at least $90 \%$ of members were African American; maintained a church membership size of at least 50 regularattending adult members (aged 50 and older) in Sunday morning services; held ongoing outreach services with at least 50 community members who received services in the last year; and were between the ages of 35 and 70 years. Pastoral representation from various prominent African American church denominations (eg, Baptist, Church of God) was also a priority. The number of churches represented consisted of Baptist (3), nondenominational (3), and Church of God (1).

Participants were informed that their participation was voluntary and a $\$ 40$ gift card was offered. A purposive convenience sampling technique was used for the study.

\section{Procedure}

Because of scant research in this area, the researchers adopted a multistep method where a brief quantitative community assessment among pastors and discussions with the community advisory board ( $\mathrm{CAB}$ ) were used to modify a qualitative research design to interview pastors.

Although the beginning of the community engagement process with churches focused on the CRC study project, the team realized that it was important to capture and conduct a variety of methods to assess the community's knowledge, beliefs, and experiences of as many health disparities among African Americans in and affiliated with these faith-based organizations. Both the team and key pastors agreed that a structured community assessment with faith-based organizations should start with inquiries about the faith-based population's perspectives of the community's current state of health and how it currently communicated health issues. The methods employed to conduct this assessment included brief surveys during community meetings and activities. 
The initial community assessment was necessary to understand the culture of faith-based organizations in Kansas and Missouri in terms of prevalent health issues among African Americans and communication about those health issues in the local church. The assessment included a health and communication component that was administered to a total of 11 pastors at 2 separate pastor luncheons within a 2-month time period. The pastors were surveyed immediately following a discussion about the CRC project and other health issues over a lunchtime session hosted by the primary author. The surveys were later tabulated, analyzed, and used to inform the development and modification of the semistructured interview guide with pastors.

In-depth interviews with pastors were then conducted following the community assessment and a meeting with $\mathrm{CAB}$ members. The researchers interviewed pastors to explore their perspectives of the effectiveness of socially marketed CRC screening promotion materials to church members. Interviews were conducted at each pastor's church for approximately 90 to 120 minutes and were digitally recorded to accurately capture responses. On an occasion, 2 members of the research team coconducted the interview. Interviews were then subsequently transcribed for analysis, and an open coding process was applied where categories are assigned to analyze data. Transcripts were read and reread first by the primary author to (1) determine data saturation and (2) develop initial categories to discuss salient themes with other team members. This process is based on the constant comparison method across transcripts to determine the similarities and differences between participants' responses. ${ }^{21}$

\section{Materials}

Following feedback from a $\mathrm{CAB}$ and community assessment, a semistructured interview guide was modified and further developed for the study (see Supplemental Appendix, available at http://links.lww.com/FCH/A3). Core discussion questions were asked of pastors and focused on church infrastructure and functioning adaptable for a CRC promotion intervention; behavioral beliefs and values around CRC screening (attitudes); normative beliefs and personal motivations/decisions on whether to get tested for CRC (subjective norms); barriers and facilitators of CRC screening and how these influence perceptions (perceived behavioral control); and opinions on the church as a sponsor of CRC targeted screening church materials. Interview questions for pastors also included additional topics to address intervention feasibility: church infrastructure (eg, church services, types of ministries and outreach services) and functioning (church-based information delivery processes, process for developing services, types of ministries and outreach services) and functioning (church-based information delivery processes, process for developing new programs); perceived challenges and facilitators for implementing a church-based CRC intervention; and issues on sustaining a CRC screening program in the church. In addition, the pastors were asked about their own beliefs about CRC.

\section{RESULTS}

\section{Community assessments}

The brief assessment was designed to get an idea of what health issues were on high priority and whether CRC fell in that list. Data gathered from pastors who participated in the community assessment prior to in-depth interviews show what health issues pastors believed to be prevalent in their congregations. While CRC was mentioned, it was not the primary cancer pastors felt was an issue among congregants. Pastors surveyed through the assessment $(\mathrm{N}=11)$ prior to in-depth interviews showed that cancer is one of the health issues that church members are facing; however, colorectal cancer was not seen as one of the cancers that members were suffering from; it was also not one of the health topics that surfaced first. The majority of clergy reported neither themselves nor anyone else in their 
congregation had talked about colon cancer openly in the church setting; however, other cancer and health disparities were discussed as issues that their congregants or congregants' family members faced. Discussion of health issues including diabetes, high blood pressure, mental health, obesity, and cancer were topics that were reported as useful to the participants. These same topics were found to be the major health issues the congregations were facing (see the Table 1). About half of the respondents reported having health ministries and of these the main health initiatives were exercise classes, cardiopulmonary resuscitation, blood pressure monitoring, and human immunodeficiency virus/AIDS.

When asked about how they communicated health issues in the church, most reported that they communicated health topics from the pulpit, in the form of sermons and announcements and do not use the mass media, nor social media to disseminate health information. Other results included the sharing of resources and opportunities to support the community through crossing denominational lines.

\section{Semistructured interviews}

Semistructured interviews were conducted with 6 men and 1 woman $(N=7)$ ranging in age from 39 to 58 years. All participants had some level of postsecondary education and had pastored their current church for at least 5 years. The time that the pastors had been in ministry ranged from 11 to 41 years and church membership varied from 100 to 500 members.

Pastor interview guides were modified to address issues that surfaced in the community assessment survey and also discussions with CAB members. The interviews with pastors yielded similar information in that all pastors indicated that colorectal cancer risk and prevention is not openly discussed in the church but pastors also reported it as a topic that should be raised and believe the church should assist in promoting this type of cancer information. One pastor expressed this in terms of avoidance and that the dosage of information could help members to start talking about CRC.

"I think it needs to be more information (in) regards to it (colorectal cancer), because I think the more information that people have, they can take it and apply it or they could take it and reject it, whichever one, but I think as far as the church is concerned, sometimes we don't like to talk about real life issues for whatever reason,or we might talk about certain issues, but certain issues we probably want to stay away from. But I believe that we have to talk about especially cancer, because cancer is raging now, so many different types of cancer. And so I just think the more information that people have is helpful for our church and every church across the board. I would say more information in helping people understand about it."

Another pastor said she felt this hesitation and avoidance is because of fear and fatalistic thinking. She believed these barriers could only be removed through knowledge and an emphasis on the immediacy of the problem.

"People have to have a sense of urgency about awareness and the only thing that's going to take away fear of awareness is to help people understand that early detection saves lives."

Pastors also believe that it is reasonable that the church could be used to communicate the importance of CRC risk and prevention among the congregation similar to other social issues such as civil engagement. The pastor's communication in particular would be effective in accomplishing this promotion. 
"For whatever reason, when the things that are promoted from the pulpit or the pastor endorses, people for whatever reason pay more attention to those things than they do otherwise. And the fact that it's driven by the pastor and other influential leaders in the church will be, I think will bring the significant amount of attention to it, whereby people will then follow those instructions. For instance, right now we're putting focus on not who to vote for in the election, but the fact that people ought to register to vote, so we have a voter registration program going on right now, but it wouldn't go as well as it is if the pastor does not emphasize it and keep it in front of the people. And, again, it would be like with these health screenings."

Even though the general consensus among these pastors was that the church could be used as a vehicle to increase communication about CRC among congregation members, there was not agreement that the church should be the primary sponsor of CRC health promotion materials when compared with traditional sponsors such as the American Cancer Society or the Centers for Disease Control and Prevention (Table 2).

Another theme throughout the interviews and preliminary discussions with CAB members was about the incorporation of humor to address the seriousness and difficulty of discussing colorectal cancer and screening for CRC.

"Just have some fun with it. Because we get so medically (focused) you're going to scare, especially African-Americans off for sure, but you're going to scare everybody off. So if you just say hey why don't you go get checked out, cancer's serious, you don't want to have any future damage. Have some fun with it, call it what you want to call it, Colorectal Cancer is real difficult even to digest. Yeah, you'll scare ... they'll get scared off right away."

\section{DISCUSSION}

The goals of the current community based participatory research project were to assess pastor personal beliefs about CRC and also the perceptions of social marketing and the feasibility of a religiously targeted CRC screening intervention utilizing pastor-delivered and church-endorsed messaging.

Overall, the researchers found that CRC is a topic that pastors feel their congregants do not discuss, mostly because of discomfort, fear, or the lack of knowledge and awareness. Pastors do believe that the church can be used as a social marketer of CRC health promotion materials and also that the church is an ideal place for CBHPPs and interventions to occur. Pastors disagreed however on whether the church should be the primary sponsor of materials and thought that sponsorship of CRC materials should be shared or cosponsored between the church and an established organization such as the American Cancer Society or a medical care organization or institution. This cosponsorship would raise credibility of the message and also the possibility of increasing awareness and adherence to cancer screening.

Within the last decade, faith-health programs and clergy-led health initiatives have increased. Some examples of this are in the creation of the White House Office of FaithBased Community Initiatives in 2000 and collaborations between the Centers for Disease Control and Prevention with groups such as the National Black Churches. ${ }^{14}$ Markens and colleagues $^{22}$ found that pastors in Los Angeles were positive about mammography promotion in churches and were appreciative to be involved with projects that positively impacted the greater community. Some pastors in the area saw the promotion program as a linkage of secular health issues (mammography) to the holistic goals of the Black church. While the number of CBHPPs has increased, there is still reservation among some about the value of CBHPPs. Pastors in this same study believed that barriers of mistrust were still 
prevalent among congregants. ${ }^{22}$ In a different research study that explored how to design social marketing strategies to increase African Americans' access to health promotion programs, Icard and colleagues ${ }^{23}$ found that the African American church could be a barrier in health promotion activities targeting at-risk African Americans. Focus group participants favored receiving information from individuals who they could trust and expressed negative views toward politicians and pastors as the source of health information. The authors state that health promotion programs must not be exclusive, leaving out groups that the church may not ordinarily reach out to such as substance abusers and drug addicts. This raises a valid question of the reach and scope of designing social marketing strategies that can be employed by the African American church. As a core part of the African American community, churches have the responsibility of not only reaching its congregation but also the surrounding community to fulfill its mission. Research shows, however, that pastors in present day are for the most part positive about impacting the health of the community $22-24$ and are concerned about the well-being of not only the congregation but also the community members regardless of stereotypes or socioeconomic status. Additional research that involves not only African American congregation member participants but also community participants surrounding the churches will inform strategy.

The information from this study has implications for subsequent development of social marketing health interventions for African Americans. The lessons here have potential impact on health promotion practice and thus social marketing strategies employed to increase the effectiveness of not only CBHPPs and interventions but also health communication campaigns targeting ethnic faith-based communities. A future study will test a social marketing model among churches and their surrounding communities where individuals will receive both sponsored materials from the church and those sponsored by another organization. The results from this study and future studies should help in addressing CRC disparities among African Americans in the Midwest and throughout the country.

\section{Acknowledgments}

The project was supported by Grant Number 1K01CA164009-01 from the National Cancer Institute. The content is solely the responsibility of the authors and does not necessarily represent the official views of the National Cancer Institute or the National Institutes of Health.

The authors thank Crystalee Masarik and Christina Pacheco for their contribution to the project.

\section{References}

1. American Cancer Society. Colorectal Cancer Facts \& Figures 2011-2013. Atlanta, GA: American Cancer Society; 2011.

2. Howlander, N.; Noone, AM.; Krapcho, M., et al. SEER Cancer Statistics Review, 1975-2008. Bethesda, MD: National Cancer Institute; http://seer.cancer.gov/csr/1975_2008/, based on November 2010 SEER data submission, posted to the SEER Web site, 2011 [Accessed October 23, 2012]

3. Centers for Disease Control and Prevention. [Accessed January 3, 2013] Colorectal cancer rates by race and ethnicity. http://www.cdc.gov/cancer/colorectal/statistics/race.htm. Published May 2, 2012

4. Agrawal S, Bhupinderjit A, Bhutani MS, et al. Colorectal cancer in African Americans. Am J Gastroenterol. 2005; 100:515-523. [PubMed: 15743345]

5. Greiner KA, Born W, Nollen N, et al. Knowledge and perceptions of colorectal cancer screening among urban African Americans. J Gen Intern Med. 2005; 20(11):977-983. [PubMed: 16307620]

6. Powe BD. Cancer fatalism among elderly African Americans: effects on colorectal cancer screening. Cancer Nurs. 1995; 18:385-392. [PubMed: 7585493] 
7. Katz ML, James AS, Pignone MP, et al. Colorectal cancer screening among African American church members: a qualitative and quantitative study of patient-provider communication. BMC Public Health. 2004; 4:62. [PubMed: 15601463]

8. Jernigan JC, Trauth JM, Neal-Ferguson D, Cartier-Ulrich C. Factors that influence cancer screening in older African American men and women: focus group findings. Fam Commun Health. 2001; 24(3):27-33.

9. King S, Burgess E, Akinyela M, et al. Your body is God's temple: the spiritual beliefs of multigenerational African American families. Res Aging. 2005; 27:420-446.

10. Lincoln, CE.; Mamiya, LH. The Black Church in the African American Experience. Durham, NC: Duke University Press; 2001.

11. Asante, MK.; Asante, KW. African Culture: The Rhythms of Unity. Westport, CT: Greenwood; 1985.

12. The Pew Forum. A religious portrait of African-Americans. [Accessed January 21, 2010] http:// www.pewforum.org/docs/?DocID=389

13. Levin JS. Roles for the Black pastor in preventative medicine. Pastoral Psychol. 1986; 35(2):94103.

14. Watson DW, Bisesi L, Tanamly S, et al. The role of small and medium-sized African American churches in promoting healthy life styles. J Relig Health. 2003; 42(3):191-200.

15. Peterson J, Atwood JR, Yates B. Key elements for church-based health promotion programs: outcomebased literature review. Public Health Nurs. 2002; 19(6):401-411. [PubMed: 12406175]

16. Campbell MK, James A, Hudson MA, et al. Improving multiple behaviors for colorectal cancer prevention among African American church members. Health Psychol. 2004; 23(5):492-502. [PubMed: 15367069]

17. Campbell MK, Hudson MA, Resnicow K, et al. Church-based health promotion interventions: evidence and lessons learned. Annu Rev Public Health. 2007; 28:213-234. [PubMed: 17155879]

18. Andreasen, A. Marketing Social Change. San Francisco, CA: Jossey-Bass; 1995.

19. National Cancer Institute. Theory at a Glance: A Guide for Health Promotion Practice. 2nd Ed.. National Cancer Institute; 2005.

20. Evans D. How social marketing works in health care. Health Promot Res. 2006; 332(20):12071210.

21. Patton, MQ, 3rd ed.. Qualitative Research \& Evaluation Methods. Thousand Oaks, CA: Sage Publications, Inc; 2002.

22. Markens S, Fox SA, Taub B, Gilbert ML. Role of Black churches in health promotion programs: lessons from the Los Angeles mammography promotion in churches program. Am J Public Health. 2002; 92(5):805-810. [PubMed: 11988451]

23. Icard LD, Bourjolly JN, Siddiqui N. Designing social marketing strategies to increase African Americans' access to health promotion programs. Health Soc Work. 2003; 28(3):214-223. [PubMed: 12971285]

24. Aholou TMC, Gale JE, Slater LM. African American clergy share perspectives on addressing sexual health and HIV prevention in premarital counseling: a pilot study. J Health. 2011; 50(2): 330-347. 
Table 1

Pastor Reported Health Issues Among Their Congregants $(\mathrm{N}=11)$

\begin{tabular}{|lccc|}
\hline Health Issue & \% Affected & Cancer Types & \% Affected \\
\hline Cancer, diabetes, high & 50 & Breast & 40 \\
blood pressure & & Prostate & 20 \\
& & Lung & 20 \\
& & Colon & 20 \\
Mental health, obesity & 33 & & \\
No response & 17 & & \\
\hline
\end{tabular}


